13.1

\title{
Формирование бикристаллических пленок ZnO на ромбоэдрической плоскости сапфира при высоких скоростях роста
}

\author{
() А.Э. Муслимов ${ }^{1}$, А.М. Исмаилов ${ }^{2}$, А.Ш. Асваров ${ }^{1,3}$, В.А. Бабаев ${ }^{2}$, В.М. Каневский ${ }^{1}$ \\ ${ }^{1}$ Институт кристаллографии им. А.В. Шубникова ФНИЦ „Кристаллография и фотоника“ РАН, Москва, Россия \\ ${ }^{2}$ Дагестанский государственный университет, Махачкала, Россия \\ ${ }^{3}$ Институт фозики им. Х.И. Амирханова Дагестанского научного центра РАН, Махачкала, Россия \\ E-mail: amuslimov@mail.ru
}

Поступило в Редакцию 5 июля 2019г.

В окончательной редакции 17 марта 2020г.

Принято к публикации 17 марта 2020г.

\begin{abstract}
Предложена методика формирования бикристаллической пленки $\mathrm{ZnO}$ с использованием особенностей метода магнетронного распыления и ориентирующего действия ромбоэдрической плоскости сапфира. Показано, что при последовательном использовании двух режимов осаждения $(\sim 2$ и $\sim 16 \mathrm{~nm} / \mathrm{s})$ формируется бикристаллическая пленка с (110)-ориентированным нижним подслоем и (002)-ориентированным верхним. Рекристаллизационный отжиг при $1000^{\circ} \mathrm{C}$ в течение $10 \mathrm{~h}$ не влияет на верхний (002)-ориентированный слой и приводит к релаксации напряжений в нижнем (110)-ориентированном слое.
\end{abstract}

Ключевые слова: оксид цинка, дифракция, бикристаллические пленки.

DOI: 10.21883/PJTF.2020.11.49501.17964

Наноразмерные структуры, занимающие небольшой объем и при этом обеспечивающие требуемый уровень функциональности, являются основой развития современной электроники. В частности, вызывает интерес продольная граница между двумя разориентированными монокристаллическими блоками в бикристаллических материалах. Исследованием таких двумерных границ занимались и ранее. Например, ее присутствием объяснялась сверхпроводимость в деформированных кристаллах олова [1]. Длительное время такие бикристаллические материалы служили модельными объектами для исследования зависимости свойств твердого тела от параметров границ зерен, механизма их передвижения [2,3], а также фазовых переходов фасетирование-дефасетирование [4]. Повышенный прикладной интерес к бикристаллическим подложкам обнаружился в начале нового тысячелетия после появления новой отрасли науки - магнитоэлектроники (спинтроники) [5]. Среди основных элементов устройств спинтроники можно назвать магнитные контакты. Эти устройства предполагают наличие границы с выраженным ориентационным переходом в определенном направлении. Одним из способов получения магнитных контактов с высоким качеством границы является использование бикристаллической границы в тонкой эпитаксиальной пленке, выращенной на бикристаллической подложке [6]. В то же время для получения бикристаллических пленок некоторых материалов можно использовать особенности их роста. Например, для материалов с гексагональной структурой наблюдается сильная тенденция к текстурированному росту вдоль оси с, направленной перпендикулярно поверхности подложки [7], а использование ориентирующих подложек и низких скоростей роста может обеспечивать получение пленок $\mathrm{ZnO}$ с заданной ориентацией [8]. В настоящей работе на примере гексагонального $\mathrm{ZnO}$ предложена методика формирования бикристаллической пленки на ромбоэдрической $(R)$ плоскости сапфира, а также исследовано влияние постростового отжига на структурное совершенство биориентированных слоев.

В качестве подложек использовались пластины $R$-плоскости сапфира, обработанные химико-механическим способом и подвергнутые дополнительному отжигу при температуре $1100^{\circ} \mathrm{C}$. Такой отжиг приводил к модифицированию поверхности монокристаллической пластины с образованием на ней террасно-ступенчатой наноструктуры [9]. Такой подход позволяет получать морфологически однородную пленку [10].

На поверхность пластин наносились пленки $\mathrm{ZnO}$ методом магнетронного распыления керамической мишени на автоматизированном напылительном комплексе „ВАТТ АМК-МИ“ (ООО „ФерриВатт“, Казань), обеспечивающем предельное остаточное давление $\sim 9 \cdot 10^{-5} \mathrm{~Pa}$. Давление рабочего газа Ar регулировалось с помощью РРГ-10 (ООО „Элточприбор“, Россия) и измерялось широкодиапазонным вакуумметром TELEVAC CC-10 (США). Нагрев подложки осуществлялся резистивным нагревателем (нихром).

Рентгеновские исследования проводились на дифрактометре X'PERT PRO (PANalytical, Нидерланды) в геометрии „на отражение“ методом Брэгга-Брентано; излучение $\mathrm{Cu}_{\alpha} \quad(\lambda=1.5418 \AA)$ с использованием $\mathrm{Ni}_{\beta}$-фильтра. Микроскопические исследования проводились на атомно-силовом микроскопе „NtegraAura“ (НТ-МДТ) в полуконтактном режиме, растровом электронном микроскопе ЈСМ-6000 с системой энергодис- 

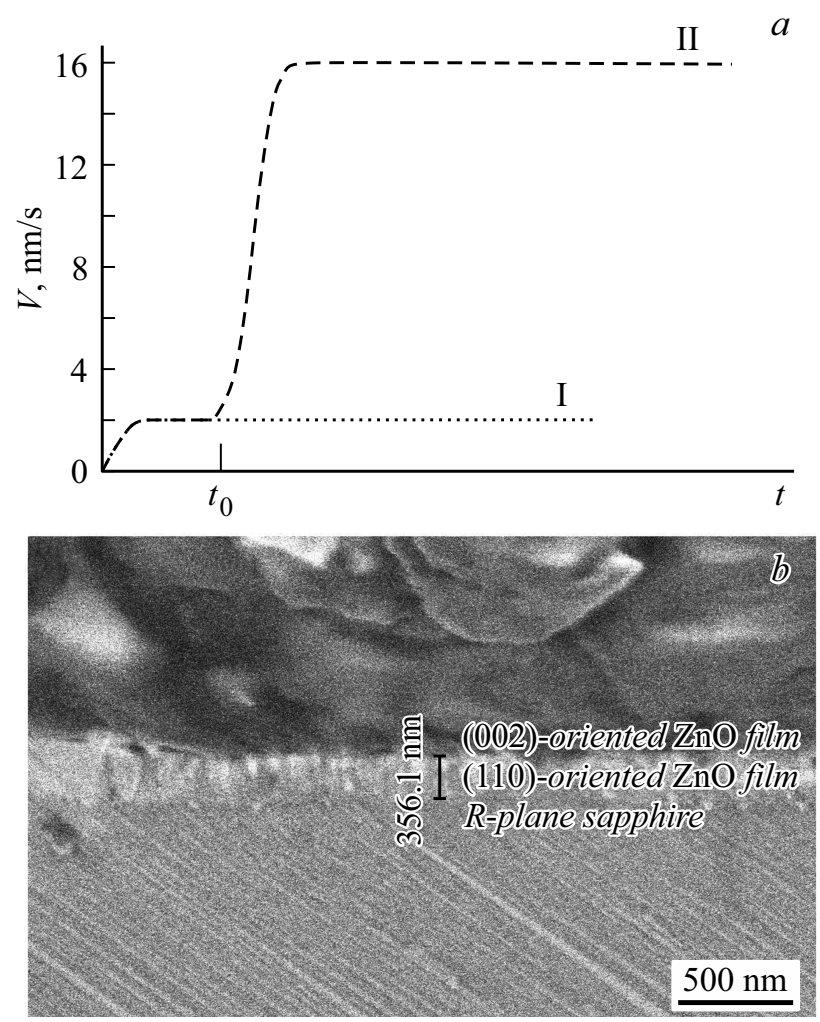

Рис. 1. Временна́я диаграмма режимов (I, II) напыления пленок $\mathrm{ZnO}$ на $R$-сапфире $(a)$ и область поперечного скола пленки $\mathrm{ZnO}$, полученной в режиме II, вблизи интерфейса с подложкой $(b)$.

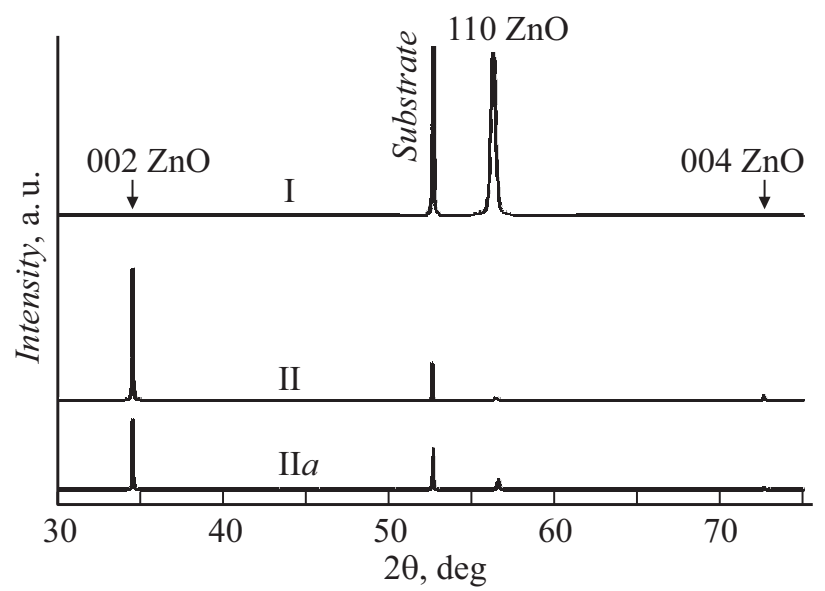

Pис. 2. Дифрактограммы пленок $\mathrm{ZnO}$ на $R$-сапфире, полученных в режимах I, II, II $a$.

персионного рентгеновского микроанализа (Jeol, Япония) и двулучевом электронно-ионном микроскопе Scios DualBeam (FEI, CША). Использование последнего в режиме ионного зонда позволило получить топографический контраст с элементами ориентационного контраста. Толщины пленок определялись с помощью интерференционного микроскопа МИИ-4 (Россия) и подтвер- ждались при исследовании поперечных срезов пленок методом электронной микроскопии.

На начальном этапе отрабатывались режимы осаждения пленок $\mathrm{ZnO}$. Давление рабочего газа в системе поддерживалось $\sim 1$ Ра. Температура подложки поддерживалась на уровне $650^{\circ} \mathrm{C}$. Рост пленок $\mathrm{ZnO}$ осуществлялся в двух режимах, соответствующих двум значениям подводимой мощности. Оценка скорости роста напыленных пленок показала, что при плотности тока разряда $\sim 20 \mathrm{~mA} / \mathrm{cm}^{2}$ скорость роста слоев $V$ составляла $2 \mathrm{~nm} / \mathrm{s}$ (режим I), тогда как при увеличении плотности тока до $500 \mathrm{~mA} / \mathrm{cm}^{2}$ скорость роста увеличивалась до $\sim 16 \mathrm{~nm} / \mathrm{s}$ (режим II). Ранее была продемонстрирована возможность роста пленок $\mathrm{ZnO}$ с высоким структурным совершенством на неориентирующих подложках при высоких скоростях роста [11]. Для предотвращения разрушения керамической мишени в результате термического удара при высоких скоростях роста в начале процесса распыления плотность тока разряда увеличивалась плавно с полкой в районе $20 \mathrm{~mA} / \mathrm{cm}^{2}$ (рис. 1,a).

Согласно данным рентгеновской дифракции (рис. 2), на спектре пленки $\mathrm{ZnO}$ толщиной $\sim 6.5 \mu \mathrm{m}$, осажденной на ориентирующую подложку в режиме I, присутствует только один рефлекс, соответствующий отражению от плоскости (110) $\mathrm{ZnO}$, что свидетельствует о формировании пленки, в которой полярная ось с кристаллитов $\mathrm{ZnO}$ направлена параллельно плоскости подложки сапфира с террасно-ступенчатой наноструктурой и совпадает с направлением ступеней на поверхности. Это обусловлено структурно-геометрическим сходством в расположении

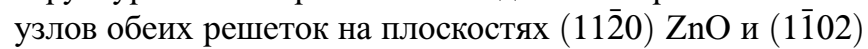
$\mathrm{Al}_{2} \mathrm{O}_{3}$ : прямоугольник (почти квадрат) со сторонами $\sim 0.5 \mathrm{~nm}[12]$.

Однако на дифрактограмме более толстой пленки $(\sim 35 \mu \mathrm{m})$, полученной в режиме II, помимо рефлекса $110 \mathrm{ZnO}$ присутствуют узкие рефлексы, соответствующие отражению от семейства плоскостей $(00 l)$. При этом интегральная ширина рефлексов от семейства плоскостей $(00 l)$ заметно меньше интегральной ширины рефлекса $110 \mathrm{ZnO}$ и близка к инструментальной ширине. На основе этого можно сделать вывод, что высокие скорости роста приводят к снижению ориентирующего действия подложки и формированию (002)-ориентированных пленок $\mathrm{ZnO}$ с высоким структурным совершенством.

При этом исследование поперечного скола пленки $\mathrm{ZnO}$, напыленной в режиме II, с помощью двулучевого микроскопа Scios DualBeam (в режиме детектирования вторичных электронов, генерируемых при сканировании ионным зондом) выявило двухслойную структуру данной пленки (рис. $1, b)$. На микрофотографии наблюдается достаточно четкая граница между двумя слоями, образующими пленку.

Сопоставление условий формирования пленок $\mathrm{ZnO}$ в двух различных режимах (рис. $1, a$ ), данных электронной 
Соотношение интенсивностей рефлексов $I_{002} / I_{110}$, параметры кристаллических решеток $a, c$, область когерентного рассеяния $D_{110}$ и соотношение $\mathrm{Zn} / \mathrm{O}$ в бикристаллической структуре (002) $\mathrm{ZnO} /(110) \mathrm{ZnO} / R$-сапфир

\begin{tabular}{c|c|c|c}
\hline $\begin{array}{c}\text { Параметры кристаллической } \\
\text { решетки для пленок ZnO }\end{array}$ & Режим I & Режим II & Режим II $a$ \\
\hline$I_{002} / I_{110}$ & - & 63.6 & 7.5 \\
$c, \mathrm{~nm}$ & - & 0.5200 & 0.5200 \\
$a, \mathrm{~nm}$ & 0.3266 & 0.3256 & 0.3250 \\
$D_{110}, \mathrm{~nm}$ & 23 & 44 & 83 \\
$\mathrm{Zn} / \mathrm{O}^{*}$ & - & 0.78 & 0.69
\end{tabular}

* По данным энергодисперсионного рентгеновского микроанализа (SEM JCM-6000).

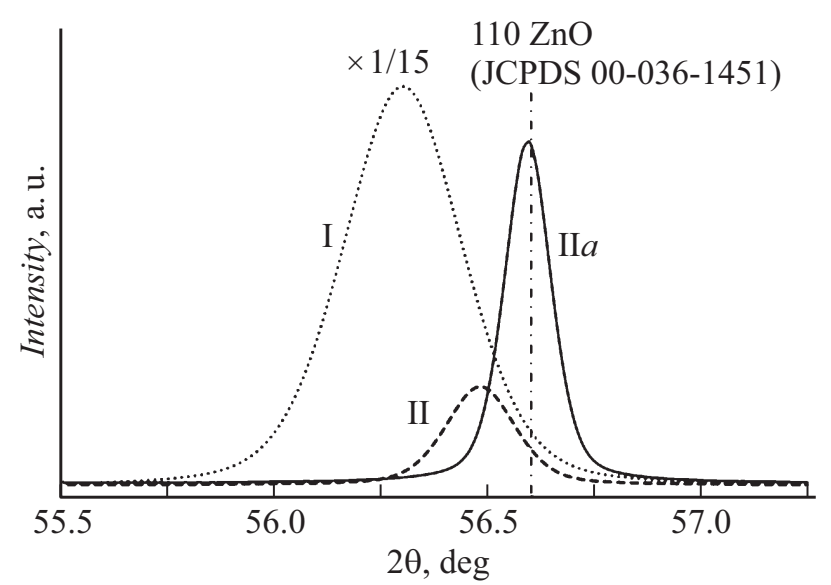

Рис. 3. Сравнительный анализ пика (110) на дифрактограммах пленок $\mathrm{ZnO}$ на $R$-сапфире, полученных в режимах I, II и II $a$.

микроскопии (рис. $1, b)$ и полученных спектров рентгеновской дифракции (рис. 2) позволяет сделать вывод, что в пленке $\mathrm{ZnO}$, напыленной в режиме II, наблюдается бикристаллическая структура. На начальном этапе при низких скоростях роста на подложке формируется тонкий (110)-ориентированный слой $\mathrm{ZnO}(\sim 350 \mathrm{~nm})$, толщина которого определяется длительностью полки $t_{0}$ на временно́й диаграмме режима напыления (рис. 1,a). При увеличении скорости роста механизм роста слоя переключается и далее формируется (002)ориентированный слой $\mathrm{ZnO}$. Результатом формирования достаточно толстого (002)-ориентированного слоя на структуре $(110) \mathrm{ZnO} /(1 \overline{1} 02) \mathrm{Al}_{2} \mathrm{O}_{3}$ является наблюдаемое снижение интенсивности как рефлекса подложки, так и рефлекса $110 \mathrm{ZnO}$ на соответствующей дифрактограмме.

Рекристаллизационный отжиг в открытой атмосфере бикристаллической пленки $\mathrm{ZnO}$, осажденной в условиях режима II, при $1000^{\circ} \mathrm{C}$ в течение $10 \mathrm{~h}$ (режим II $a$ ) приводит к заметному изменению соотношения интенсивности рефлексов 002 и 110 (дифрактограмма II $a$ на рис. 2). При этом форма рефлекса $002 \mathrm{ZnO}$ и его угловое положение почти не менялись, а рефлекс $110 \mathrm{ZnO}$ значительно видоизменялся (рис. 3). В табли- це обобщены данные рентгеновской дифракции пленок $\mathrm{ZnO}$, выращенных в режимах I, II и II $a$. Приведенные на рис. 3 и в таблице данные свидетельствуют о том, что в исходной бикристаллической пленке нижний (110)-ориентированный слой по сравнению с верхним (002)-ориентированным слоем обладает более заметными внутренними дефектами и напряжениями, которые релаксируют в ходе отжига. Возможно, также имеет место разрастание (110)-кристаллитов за счет лежащих поверх (001)-кристаллитов, однако утверждать это однозначно, используя только данные рентгеновских методов исследований, нельзя.

Менее значительный сдвиг в сторону меньших углов $2 \theta$ и меньшая интегральная ширина рефлекса 110 в бикристаллической пленке $\mathrm{ZnO}$, напыленной в режиме II, чем в случае (110)-ориентированной пленки $\mathrm{ZnO}$ (режим I), можно объяснить присутствующим в режиме II дополнительным подводом тепловой энергии к поверхности роста за счет излучения магнетронного разряда при больших плотностях тока.

В конечном итоге результатом рекристаллизационного отжига бикристаллической пленки $\mathrm{ZnO}$ главным образом является улучшение кристалличности нижнего (110)-ориентированного слоя за счет снижения механических макро- и микронапряжений и отжига дефектов типа вакансии кислорода $V_{\mathrm{O}}$ и межузельного цинка $\mathrm{Zn}_{i}$.

Таким образом, в работе предложена методика формирования бикристаллической пленки $\mathrm{ZnO}$ с использованием особенностей метода магнетронного распыления и ориентирующего действия ромбоэдрической плоскости сапфира. Показано, что при малых скоростях роста ( $\sim 2 \mathrm{~nm} / \mathrm{s})$ на $R$-плоскости сапфира формируется тонкий (110)-ориентированный слой ZnO. При последовательном использовании двух режимов осаждения $(\sim 2$ и $\sim 16 \mathrm{~nm} / \mathrm{s})$ на подложке формируется бикристаллическая пленка с (110)-ориентированным нижним подслоем и (002)-ориентированным верхним. Последующий рекристаллизационный отжиг бикристаллической пленки $\mathrm{ZnO}$ в открытой атмосфере при $1000^{\circ} \mathrm{C}$ в течение $10 \mathrm{~h}$ приводит к заметному изменению соотношения интенсивностей рефлексов 002 и 110 на дифрактограмме. Анализ дифракционных данных показывает, что в исходной бикристаллической пленке нижний (110)-ориентированный слой по сравнению с верхним (002)-ориентированным слоем обладает более заметными внутренними дефектами и напряжениями, которые релаксируют в результате отжига.

\section{Финансирование работы}

Работа выполнена при поддержке Министерства науки и высшего образования РФ в рамках выполнения работ по Государственным заданиям ФНИЦ „Кристаллография и фотоника“ РАН в части „получения пленок“ и Дагестанского федерального исследовательского центра РАН в части „структурной диагностики пленок“ с использованием оборудования Центра коллективного пользо- 
вания „Структурная диагностика материалов“ ФНИЦ „Кристаллография и фотоника“ РАН и Аналитического центра коллективного пользования ДФИЦ РАН, а также при поддержке Российского фонда фундаментальных исследований (грант № 18-29-12099 мк).

\section{Конфликт интересов}

Авторы заявляют, что у них нет конфликта интересов.

\section{Список литературы}

[1] Хлюстиков И.Н., Хайкин М.С. // ЖЭТФ. 1978. Т. 75. В. 3. C. $1158-1160$.

[2] Amiri-Hezaveh A., Balluffi R.W. // Rev. Sci. Instrum. 1993. V. 64. N 10. P. 2983-2992.

[3] Gorkaya T., Molodov D.A., Gottstein G. // Acta Mater. 2009. V. 57. N 18. P. 5396-5405.

[4] Straumal B.B., Polyakov S.A., Bischoff E., Mittemeijer E.J., Gust W. // Def. Diff. Forum. 2003. V. 216-217. P. 93-100.

[5] Иванов В.А., Аминов Т.Г., Новоториев В.М., Калинников В.Т. // Изв. АН. Сер. хим. 2004. № 11. С. 2255-2303.

[6] Mathur N.D., Burnell G., Isaac S.P., Jackson T.J., Teo B.-S., MacManus-Driscoll J.L., Cohen L.F., Evetts J.E., Blamire M.G. // Nature. 1997. V. 387. N 6630. P. 266-268.

[7] Абдуев А.Х., Асваров А.Ш., Ахмедов А.К., Эмиров Р.М., Беляев В.В. // Письма в ЖТФ. 2017. Т. 43. В. 22. С. 40-47.

[8] Moriyama T., Fujita Sh. // Jpn. J. Appl. Phys. 2005. V. 44. N 11R. P. 7919-7921.

[9] Буташин А.В., Власов В.П., Каневский В.М., Муслимов А.Э., Федоров В.А. // Кристаллография. 2012. Т. 57. № 6. C. 927-933.

[10] Муслимов А.Э., Исмаилов А.М., Бабаев В.А., Каневский В.M. // Кристаллография. 2019. Т. 64. № 5. С. 790 795.

[11] Исмаилов А.М., Эмирасланова Л.Л., Рабаданов М.Х., Рабаданов М.Р., Алиев И.Ш. // Письма в ЖТФ. 2018. Т. 44. B. 12. C. $52-61$.

[12] Meyer B., Marx D. // Phys. Rev. B. 2003. V. 67. N 3. P. 035403. 